\title{
Agent-based Simulation of Multiple-round Timber Combinatorial Auction
}

\begin{tabular}{|r|l|}
\hline Journal: & Canadian Journal of Forest Research \\
\hline Manuscript ID & cjfr-2015-0125.R2 \\
\hline Manuscript Type: & Article \\
\hline Date Submitted by the Author: & $20-$ May-2016 \\
\hline Complete List of Authors: & $\begin{array}{l}\text { Farnia, Farnoush; Ecole Polytechnique de Montreal, Department of } \\
\text { Mathematics and Industrial Engineering } \\
\text { Frayret, Jean-Marc; Ecole Polytechnique de Montreal, } \\
\text { LeBel, Luc; Universite Laval, } \\
\text { Beaudry, Catherine; Ecole Polytechnique de Montreal, }\end{array}$ \\
\hline Keyword: & $\begin{array}{l}\text { Timber Auction, Combinatorial Auction, Learning Strategy, Multi-agent } \\
\text { Simulation, Multi-round Auction }\end{array}$ \\
\hline &
\end{tabular}

SCHOLARONE ${ }^{\text {M }}$

Manuscripts 


\section{Auction}

1,2,3 École Polytechnique de Montréal

Département de mathématiques et génie industriel

2500, chemin de Polytechnique

Montréal, Québec

H3T 1J4, Canada

1 farnoush.farnia@polymtl.ca

2 jean-marc.frayret@polymtl.ca

3 Luc.Lebel@sbf.ulaval.ca

\section{Université Laval}

Département des sciences du bois et de la forêt

Faculté de foresterie, de géographie et de géomatique Québec, Québec

G1V 0A6, Canada 
7 Abstract:

8 This paper presents a simulation-based analysis of a multiple-round timber combinatorial

9 auction in the timber industry. Currently, most timber auctions are single-unit auctions

10 (i.e., each forest stand is sold separately). However, other types of auctions could be

11 applied to take advantage of the various needs of the bidders with respect to species,

12 volumes and quality. This study aims to analyze the use of combinatorial auction to this

13 specific context using a simulation approach. Various number of auctions per year,

14 periodicity, lot size, and number of bidders are considered as parameters to set up the

15 different market configurations. The outcomes of both combinatorial auction and single-

16 unit auction are compared with respect to different setup configurations. This analysis

17 shows that combinatorial auction can bring more profit for both seller and buyer when the

18 market is less competitive.

19 Keywords: Timber auction, combinatorial auction, learning strategy, multi-agent

20 simulation 


\section{$21 \quad 1 \quad$ Introduction}

22 Several problems plagued the timber market in Québec in recent years: decrease in forest

23 activities, drop in lumber sales, and constrained access to wood supplies. One issue

24 relates specifically to long-term exclusive timber licences: the wood supplies of a timber

25 licence may not always match the company's needs at a specific time. Consequently,

26 allocating timber access to suitable companies for a defined period has been one of the

27 main problems for the Québec government. The timber lots were previously assigned

28 through licencing. In the new forest regime now in place in Québec, auctions are applied

29 in order to assign $25 \%$ of timber lots. This new regime results in more flexible access to

30 timber, and in establishing timber licence prices.

31 Two main types of auctions for timber allocations exist: single-unit auctions and

32 combinatorial auctions. On the one hand, in a single-unit auction, the seller aims to sell

33 the whole lot to one bidder. In general, most timber auctions use the single-unit method

34 because of its ease of implementation. When the winner of each lot is announced, the

35 winner has a specific period to access the lot according to its need. The Québec

36 government uses single-unit auctions to allocate timber access to buyers who are willing

37 to pay more for entire lots.

38 On the other hand, timber combinatorial auctions may have some advantages over single-

39 unit auctions. These more complex auctions allow bidders to bid on any combination (i.e.,

40 bundle) of items according to their needs. Here, items are not geographically defined

41 forest stands. For example, they can be defined as specific volumes (lots) of a specific

42 mix of species and quality within a given stand. Therefore, mixed forest stands can be

43 sold to potential users. In order to identify the winners, the auctioneer calculates the 
44 highest value of the bundles. Once identified, the winners must agree on a specific time

45 to harvest the stand in which they share access.

46 A main advantage of combinatorial timber auction over single-unit timber auction is its

47 ability to consider the individual values of the products available in a mixed forest stand.

48 While mixed forest stands can be sold with a single-unit auction, the latter fails to obtain

49 the best combination of values for each single product. Therefore, the combinatorial

50 auction is more complex timber auction process. The objective of this paper is to

51 experimentally compare both types of auction within a controlled environment using

52 simulation.

53 In this paper, timber combinatorial auction are studied as an interaction procedure

54 between an auctioneering agent and several bidding agents to assign timber quantities.

55 The auctioneer (i.e. government agents) announces several different lots with defined

56 types of products (i.e., mix of species and quality) to the market on a regular basis

57 through combinatorial auctions. The bidders (i.e., forest companies and entrepreneur

58 agents) offer sealed bids for any bundle of products of the lots announced at each round.

59 The bidders are not allowed to change their offers after submitting their bids. As

60 mentioned above, the auctioneer chooses the winners according to the highest value of

61 the bundles, and the bidders must agree on a specific time to harvest the stand. In order to

62 study these interactions and this type of procedure, a simulation model was developed.

63 The simulation model is limited to four types of products; softwood and hardwood, each

64 with two levels of qualities. 
65 The simulation model contains a framework to follow the dynamics of the auctions 66 systems over the course of several rounds. Agent-based modelling was used to design and

67 implement different agent behaviours. It was used to simulate realistic bidding agents, 68 auctioneer agent, and auction mechanisms, including realistic bidding patterns and the 69 auctioneer's winner determination process.

70 This paper, which extends Farnia et al. (2013), explores how the outcomes of

71 combinatorial auctions in terms of selling price per $\mathrm{m}^{3}$ (i.e., revenue of the seller) and

72 bidders' procurement target achievement can change in different setup configurations. In

73 addition, the study compares the revenue stream of the seller and the target achievement

74 of the bidders of combinatorial auctions and single-unit auctions using multiple 75 simulations.

76 The remainder of the paper is organized as follows. In Section 2, the theoretical 77 background is presented in details. The research objective is described in Section 3. In

78 Section 4, the simulated multi-period timber combinatorial auction model is described.

79 Results and discussions including four different experiments are presented in Section 5.

80 Finally, Section 6 concludes the paper and presents a brief overview of future research.

\section{Theoretical Background}

82 In this section, the theoretical background of the research is presented in three sub-

83 sections: timber auctions, multiple-round auctions, and previous work and contribution of 84 this paper. 


\section{$85 \quad 2.1 \quad$ Timber auctions}

86 Timber allocation and pricing is of specific interest in Québec, as well as in several

87 jurisdictions in the world. Many auction models have been used to solve timber allocation

88 problems. The timber action studies have been focused on comparing open and closed

89 auctions (Mead, 1967; Hansen, 1985; Athey et al., 2011), reserve price (Paarsch, 1997;

90 Elyakime et al., 1994, 1997), collusion (Baldwin et al., 1997), competition and

91 information (Athey and Levin, 2001), and timber resale market (Haile, 2001).

92 Cramton et al. (2006) described a combinatorial auction model as a method of assigning

93 products to buyers. However, they did not compare the single-unit auction with

94 combinatorial auction. In a timber combinatorial auction, several types of products (e.g.,

95 species) are for sale, and bidders can bid on any bundle of them. The bundle of bids that

96 maximizes their combined value defines the winning bids. Combinatorial auctions can be

97 used in many applications. Resource allocation can be solved through combinatorial

98 auction, e.g., allocating airport landing time periods to airlines (i.e., Rassenti et al., 1982;

99 Ghassemi Tari and Alaei, 2013; Wang and Dargahi, 2013). Combinatorial auctions are

100 also useful for scheduling problems of loading cranes in Maritime terminals (i.e., Brewer,

101 1999; De Vries and Vohra, 2003; Cramton et al., 2006; Jung and Kim, 2006). However,

102 in the specific case of timber auctions, combinatorial auctions can have some downsides

103 compared to single-unit actions. Timber combinational auctions may result in the

104 disturbance of remaining resources, the need to spend money on clearing the logged site,

105 and/or the damage of the forest ecosystem. 


\section{$106 \quad 2.2$ Multiple-round auctions and auction simulation}

107 Multiple-round auctions are a series of auctions that are announced sequentially. At each

108 round, one or many auctions are announced simultaneously. Once a round is completed

109 and the winners identified, the auctioneer announces new auctions, sometime after a

110 delay (Grossklags et al., 2000). In the case of a multiple-round combinatorial auction,

111 each auction includes several types of products and bidders bid sequentially on any

112 bundle of them. This type of auction is used in Lau et al. (2007) in order to solve a large-

113 scale scheduling problem. In their model, to schedule jobs to the bidders, each job agent

114 submits a determined list of jobs using multiple-round combinatorial auction. Along the

115 same line, Kwon et al. (2005) proposed a multiple-round combinatorial auction for

116 truckload procurement that can be beneficial for both carriers and shippers by assigning

117 better service allocations.

118 Iterative auction is slightly different from multi-round combinatorial auction. Parkes

119 (2006) explained iterative combinatorial auction as several combinatorial auctions that

120 happen over a period of several rounds. In an iterative combinatorial auction, the bidders

121 can change their bid values according to the past rounds. Therefore, the bidders bid for

122 the bundles they want, and they can always improve their bids in the next rounds.

123 However, in a multi-round combinatorial auction, once bidders submit their bids they

124 cannot change them in next rounds.

125 Multi-agent simulation is an efficient method to simulate and analyze such auction 126 systems (Vidal, 2007). Multi-agent simulation, or agent-based simulation, models the 127 behaviours and interactions of the actors of a system (e.g., bidders, auctioneer). This

128 simulation approach involves a computerized model of a system that consists of reactive, 
129 intelligent or goal-driven agents that interact with each other and their environment. Such

130 agents manage their actions within the simulated environment. They can even have goal-

131 directed behaviours. In other words, agent-based simulation is a tool to study complex

132 systems that are difficult, if not impossible, to study analytically. For instance, agent-

133 based simulation can be used to investigate winner selection and intelligent bidders'

134 behaviour.

135 One of the challenges in designing and simulating auction systems is the randomness of 136 the parameters of the simulated auction model (Shoham and Leyton-Brown, 2009). We

137 are aware of few published papers regarding combinatorial auction using agent-based

138 systems. For example, Kutanglui and $\mathrm{Wu}$ (2001) used combinatorial auction as an

139 autonomous distributed scheduling system. They used iterative bidding process to

140 optimize job shop scheduling problem.

\section{$141 \quad 2.3 \quad$ Previous work and the contribution of this paper}

142 In order to study the impacts of various configurations of auctions in the Québec timber

143 industry, Farnia et al. (2013) used agent-based simulation. In particular, we modelled a

144 multiple-round single-unit first-price sealed-bid timber auction system using different

145 types of bidder agents (i.e., reactive agent, learning agent, adaptive agent). In this

146 simulation model, several auctions are announced simultaneously. Bidders must bid (or

147 ignore) in all auctions simultaneously during that round. The results of this study suggest

148 that adaptive and learning bidding behaviours have the best outcome according to goal 149 achievement and cost minimization, respectively. We also analyzed how the auction 150 outcome is affected by different auction configurations. 
151 Later, Farnia et al. (2015) proposed a time-based timber combinatorial auction. To the

152 basic timber criteria (i.e., quality and species), the authors add a timetable as a criterion in

153 order to address harvest operations coordination directly in the winner determination

154 process. However, experiments were limited to simulations of one combinatorial auction

155 at a time, in order to study the impacts of various behaviours on the auction outcome. To

156 our knowledge, there is no study of multiple-round timber combinatorial auctions and no

157 study that compares the performance of multiple-round combinatorial auctions and

158 multiple-round single-unit auctions. This paper aims to fill this gap by experimentally

159 comparing multiple-round single-unit and combinatorial auctions in a dynamic

160 environment over one simulated year of timber procurement.

\section{Multiple-round Timber Combinatorial Auction Model}

162 The simulation models presented hereafter builds up on the model proposed in Farnia et

163 al. (2013) by including all the necessary elements required for the simulation of

164 combinatorial timber auction. This section presents this model.

\section{$165 \quad 3.1 \quad$ Auction context}

166 In practice, an auction involves an auctioneer, a seller, and several bidders, although the

167 seller could take the role of auctioneer. In the Québec timber auction system, the 168 auctioneer, or government agency, announces and controls the auction as well as the

169 attribution process. The seller, the province of Québec, offers timber products to the

170 market. The bidders are the auction participants. For simplification, the proposed

171 simulation model only considers the auctioneer and the bidders. Similarly, we assumed

172 that each forest stand consists of four different classes of quality and species, which are 
173 sold as a whole. These classes were developed with the help of the Bureau de mise en

174 marché des bois of the Québec government. They represent softwood and hardwood,

175 each with two levels of qualities. In the remainder of this paper, these classes are referred

176 to as species or products. Therefore, there are four different types of products, including

177 softwood of quality 1 and 2 (s1, s2), and hardwood of quality 1 and $2(\mathrm{~h} 1, \mathrm{~h} 2)$. In order to

178 create a more realistic model, each lot has other specifications that make them different

179 from each other. These specifications include the location of the forest stand and the

180 volume of each species. The location of each forest stand is randomly defined during

181 simulation, while their lot size (i.e., size of forest stand) is defined at the start of the

182 simulation. The volumes by species are randomly defined according to the lot size.

183 There are three types of bidders in this model: softwood mills, hardwood mills, and

184 entrepreneurs. This segmentation is done according to the supply need of the bidders.

185 Softwood mills require softwood, and include lumber mills and paper mills. Hardwood

186 mills are interested in hardwood. Entrepreneurs are interested in both softwood and

187 hardwood products. In our model, it is considered that softwood mills mostly bid for the

188 bundles that include s1 and s2. These bundles are considered as s1, s2, s1s2, and

$189 \mathrm{~s} 1 \mathrm{~s} 2 \mathrm{~h} 1 \mathrm{~h} 2$. Large softwood mills might bid for s1, s2, or any bundle that contains s1 and

190 s2, while small softwood mills might only bid for either s1 or s2. If a softwood mill wins

191 bundle s1s2h1h2, the mill will resell the undesired volumes to other mills. The illustrated

192 example also applies to hardwood mills that may be interested in h1, h2, h1h2, and

$193 \mathrm{~s} 1 \mathrm{~s} 2 \mathrm{~h} 1 \mathrm{~h} 2$. The entrepreneurs are also interested in any bundles of s1, s2, h1, and h2. In

194 order to simplify the simulation model, and particularly the winner determination process, 
195 as well as to reduce the number of combinations that significantly increase simulation

196 time, entrepreneurs only bid for s1, s2, s1s2, h1, h2, h1h2, and s1s2h1h2 bundles.

197 The parameters of bidder agents include the type of bidder, its location, its capacity per 198 year (which defines their total need), supply needs for each species per year, and their

199 own market prices (i.e., the selling price of their own products). In this simulation model,

200 we also define several parameters that define the configuration of the auctions and the

201 auction environment. These parameters include number of auctions per year, auction

202 periodicity, number of bidders and lot size. Other parameters of the model are either

203 random within a realistic range or fixed.

\section{$204 \quad 3.2 \quad$ Simulation procedure}

205 The general simulation procedure is as follows: The products of several forest stands are 206 sold over the simulation horizon (one year) via combinatorial auctions. The products of 207 each stand are sold simultaneously during one single combinatorial auction. In other 208 words, each stand is sold individually with one combinatorial auction, which is 209 announced and processed individually. At the start of the simulation, the auctioneer 210 announces several combinatorial auctions simultaneously. So each combinatorial auction

211 concerns one specific forest stand, and bidders bid on any bundle of that stand. The

212 auctioneer announces the available products specifying the volume of each species and

213 the location of the corresponding stand. In order to simplify the simulation of the auction,

214 the reserve price of each bundle is also announced, although in the case study on which

215 we base our simulation this information remains private. For each auction, the bidders bid

216 on any combination of products composing the stand. In order to do that, bidder agents

217 have specific behaviours detailed in Farnia et al. (2013) and outlined in Section 3.3. In 
218 brief, bidder agents have a random behaviour that is between a pure adaptive behaviour

219 (i.e., capable of adapting the value of their bid according to their goal achievement level

220 and the time left to achieve it) and pure learning behaviour (i.e., capable of adjusting the

221 value of their bid according to the market value inferred through past auction outcomes).

222 After receiving the bids, the auctioneer chooses the winners according to a winner

223 determination algorithm, which is detailed in Appendix 1. Because the auction is

224 combinatorial, each stand may be assigned to one or more bidders. After announcing the

225 winners, the bidders must coordinate harvest operations. The supply needs of the winners

226 are updated according to the product allocation, which affects their behaviour in

227 remaining rounds of auction.

\section{$228 \quad 3.3 \quad$ Bidder agent behaviour}

229 In order to have realistic simulation, the bidding behaviour inspired by Farnia et al.

230 (2013) uses an adaptive learning approach in the context of a single-unit auction. This

231 approach combines two types of behaviour: a learning behaviour and an adaptive

232 behaviour. Similarly to Farnia et al. (2013), we compare the adaptive learning behaviour

233 with other realistic approaches. On the one hand, the learning behaviour considers the

234 history (i.e., past rounds of the auction) to define a bidding function, the aim of avoiding

235 over-bidding (i.e., bidding over market value). This behaviour was deemed the most

236 profitable for the bidder. On the other hand, the adaptive behaviour considers the bidder's

237 current needs and the time left to fulfill the remaining needs. This bidding behaviour was

238 the most capable of fulfilling supply needs. Bidders value each bundle of products in the

239 lot for sale. The sets and indexes to calculate the value of each bundle are indicated in 240 Table 1. 
241 The bidders need to calculate their maximum and minimum values for each bundle. The

242 minimum value of bidder $j$ for bundle $\mathrm{S}$ is considered to be equal to the reserve price of

243 bundle $\mathrm{S}$. The reserve price of bundle $\mathrm{S}$ is equal to the sum of the reserve prices of the

244 species including in that bundle. The maximum value of bidder $j$ for bundle $\mathrm{S}$ is shown in

245 Equation (1)

249 As described in Farnia et al. (2013) the bidders may face several combinatorial auctions

250 at each round of the auction. Therefore, bidders use a decision method to decide on which

251 auction to participate and which bundles to consider. The decision problem is described

252 as the following binary integer programming.

maximize:

$$
\sum_{S} \frac{V_{S}}{D_{j, S}} x_{S}
$$

subject to:

$$
\begin{aligned}
& M P_{j, S} x_{S}>R P_{S} \quad \forall S \\
& \sum_{S} V_{S} x_{S}<N D_{j, S} \\
& x_{S}=\{0,1\} \quad \forall S
\end{aligned}
$$

253 In this mathematical programming, bidder $j$ assigns a weight to each desirable bundle in 254 each round. In order to maximize the volume while minimizing the distance to obtain the 
255 bundle, the bidder defines a weight as the volume of the bundle over the distance of the

256 bundle to the bidder's mill (Equation 2). Constraint (3) confirms that the bidder considers

257 only the feasible bundles (the maximum price of the bidder is higher than the reserved

258 price of the bundle). In order to avoid bidding on more items than needed, Constraint (4)

259 ensures that the sum of the selected bundles is less than the bidder's need, which also

260 considers a small buffer to account for lost bids. Equation (5) shows the binary constraint.

261 Next, the valuation function of the bidders' bidding approach is described in Equation (6),

262 as suggested in Farnia et al. (2013), and adapted to consider bundles instead of lots.

$$
v_{j, S}=\alpha\left(\frac{M P_{j, S}-N P_{j, S}}{2}\right) * \tanh \left(\frac{f_{1}(y)}{f_{2}(d)} * \frac{f_{j 3}(n)}{f_{j 4}(c)}-2\right)+\gamma\left(\frac{M P_{j, S}+N P_{j, S}}{2}\right)+(1-\gamma) y_{j, S}
$$

263 In this equation, $v_{j, S}$ is the valuation function of bidder $j$ for bundle $\mathrm{S}, f_{1}(y)$ is the total

264 duration of the procurement process to achieve a target procurement volume (i.e., a year),

265 and $f_{2}(d)$ is the duration of the time remaining at any specific moment in the simulation

266 to achieve that target. Next, $f_{j 4}(c)$ and $f_{j 3}(n)$ are, respectively, the target supply volume

267 of bidder $j$, and the volume remaining at any specific moment in the simulation to achieve

268 the target procurement volume. The first two elements of Equation (6) represent the

269 adaptive part of the valuation function. The target supply volume of a bidder is a global

270 target (for all species). These two elements of the equation aim to create a behaviour that

271 increases the bid value when the bidder's procurement target achievement is low and

272 when the time remaining to achieve it is short. In other words, it aims to emulate the

273 procurement managers' reaction to stress with respect to how far it is to its objectives. $\alpha$

274 aims to create a different level of resistance to stress. 
$275 y_{i, S}$ is the learning part of the adaptive learning behaviour. For example, if S consists of 276 species $\mathrm{s} 1$ and $\mathrm{s} 2, y_{i, S}$ for these species is calculated according to Equation (7). We 277 estimate the coefficients of this equation using a regression analysis on the history of the 278 auction. More details can be found in Farnia et al. (2013). At each round, the bidders 279 consider the winning history and extract the information including the location of the 280 winner and the winning price of each bundle. As each bundle is considered separately, 281 there are less data available to compute Equation 7 than when species are considered. 282 This may affect the capacity of the learning part to anticipate a valid bidding price.

283 Eventually, when not enough data is available, bidders estimate the bidding price of a 284 bundle according to the price history of a single species. More specifically, bidders 285 estimate the coefficients $\left(\beta_{0}, \beta_{1}, \beta_{2} \ldots\right)$ of the regression function at each round and for 286 each bundle, adding the most recent information about the winning bids. Next, once the 287 coefficients are estimated, and using the information of the current auction, the bidder 288 anticipates the value $y_{j, s 1 s 2}$ of the bundle, with $x_{j, s 1}$ and $x_{j, s 2}$ being the volume of s1 and 289 the volume of s2 in bundle s1s2, respectively, using Equation (7). Next, the offer of 290 bidder $v_{j, s 1, s 2}$ is calculated with Equation (6).

$$
y_{j, s 1 s 2}=\beta_{0}+\beta_{1} D_{j, s 1 s 2}+\beta_{2} x_{j, s 1}+\beta_{3} x_{j, s 2}
$$

292 In Equation (6), $\alpha$ and $\gamma$ are defined as coefficients that vary within the interval [0;1]. In

293 this model bidders behave according to their specific values of $\alpha$ and $\gamma$ that are given to 294 them during the setup phase of the simulation. The valuation function is purely adaptive 295 if $\alpha=\gamma=1$. When $\alpha=\gamma=0$, the valuation function is strictly based on learning. 


\section{$296 \quad 3.4 \quad$ Winner determination}

297 This section introduces the winner determination algorithm for the simulated

298 combinatorial auction. As previously explained in Section 3.1, different kind of bidders

299 are interested in different combinations of products. The winner determination algorithm

300 is presented in Appendix 1. The algorithm shows the winner determination procedure that

301 is triggered within the simulation to determine the solution of each auction. The outcome

302 of this procedure selects $w_{s 1}, w_{s 2}, w_{h 1}$ and $w_{h 2}$, which are the winners of species $\mathrm{s} 1, \mathrm{~s} 2, \mathrm{~h} 1$,

303 and h2, respectively. The winners of each species can be similar or different. This

304 procedure only aims to identify the highest value of a fix and small number of

305 combinations. In reality, the number of combinations can be much higher and require

306 more advanced algorithms.

\section{Results and Discussion}

308 Using this simulation model, we carried out a simulation experiment described in the next

309 section. Then, using the results of this experiment, four specific analyses are presented in

310 the following sections. First, we examine the outcomes of the combinatorial auction

311 simulation in terms of average unit selling price for the seller (Analysis 1) and in terms of

312 procurement target achievement for the bidders (Analysis 2). For a bidder, Procurement

313 target achievement is the ratio of the total volume won in all rounds over its total need for

314 the entire horizon. Then, we compare these results with those obtained with single-unit

315 auctions as presented in Farnia et al. (2013) (Analysis 3 and 4). 


\subsection{Simulation experiment description}

317 In order to study these elements, we carried out a large simulation experiment with the 318 simulation model introduced in the previous section. More specifically, the experiment

319 proposes a series of sensitivity analysis of the impacts of several parameters on the

320 average unit price $\left(\$ / \mathrm{m}^{3}\right)$ and procurement target achievement (\%) of the combinatorial

321 auction. The parameters that can be changed in the model are as follows:

322

33215 , and 30 days. The three lot sizes are $10,000,15,000$, and $20,000 \mathrm{~m}^{3}$. Finally, the

333 number of bidders is set to 100,150 , and 200 . The number of bidders represents the total

334 number of companies that could participate in an auction. However, for any specific

335 auction, the number of companies that actually bid is far smaller (from two to eight)

336 because they are geographically far from the stand, or are simply not interested in bidding

337 according to their needs. When the number of bidders in simulation model set to 100,150 ,

338 and 200, the actual number of bidders for each auction is 2-4, 4-6, 6-8 respectively. All $3^{4}$ 
339 (81) configurations of these parameter levels were tested. For each configuration, the

340 experiments are repeated 25 times for a total of 2,025 experiments.

341 In this study, within each simulation, lot size is the same for all lots in all auctions.

342 Therefore, there is no possible scale economy to be gained from large lots. This limitation

343 does not affect the general results, although it limits our ability to properly evaluate the

344 impacts of simultaneous auctions with variable lot sizes, which could lead to scale

345 economies. This remains for future work to address.

\section{$346 \quad 4.2 \quad$ Analysis 1 - Average unit price}

347 Table 2 shows the analysis of variance for the average unit price (i.e., dependent variable)

348 resulting from the combinatorial auctions. In order to simplify the analysis, these studies

349 only analyze the effects of each parameter (i.e., independent variable) and all

350 combinations of any two of them. The ANOVA studies show a $\mathrm{R}^{2}$ above 0.80 , which

351 indicates a reasonable level of statistical certainty. The results show that the only

352 significant parameters are the number of auctions, the lot size, the number of bidders, and

353 the combined effect of the number of auctions and lot size.

354 Figure 1 illustrates the effects of each parameter. As shown, when the number of auctions 355 increases, the average unit price decreases due to more supply on the market (i.e., all

356 things being equal, when more supplies are available, the price drops). The average unit

357 price also diminishes when the lots get larger, again because of more supply. When the

358 number of bidders increases, so too does the price. The slope of increasing price is higher

359 between 100 to 150 compare to 150 to 200 . The reason is that in the lower range of the

360 number of bidders in the market, the price is more sensitive to competitiveness. Where as 
361 when there are more potential bidders the price tends to move towards its market value.

362 Along this line, the price also decreases when the number of auctions increases, even if

363 lot size changes. However, the price is lower when the lot size gets larger. The reason for

364 this result is that both the number of auctions and the lot size significantly increase

365 supply. That is one side of argument. Other side - larger the lot size, there are economies

366 of scale in harvesting operations, so bidders may be willing to pay high prices compared

367 to smaller lots. However we did not consider this element in our model. This can be

368 considered in future studies. Therefore, the combination of these two parameters affects

369 the average unit price. These intuitive results tend to validate the simulation model.

\section{$370 \quad 4.3 \quad$ Analysis 2 - Procurement target achievement}

371 We analyzed the effect of the same parameters (i.e., number of auctions, periodicity, lot

372 size, and number of bidders) on the average target achievement of the bidders. Table 3

373 shows the analysis of the variance of the parameters on the target achievement. As shown

374 in this table, the parameters contribute to explaining more than $98 \%$ of the variance of the

375 target achievement. All the analyzed parameters have a significant effect.

377 To illustrate the analysis of variance, Figure 2 shows the effects of single parameters.

378 Both the number of auctions and the lot size show a positive impact, while periodicity

379 and number of bidders have a negative impact on the target achievement. The reasons for

380 the positive impact is there are more timber through the auction system, thus bidders can

381 win more timber supply to fulfill their needs. Similarly, when the number of bidders rises,

382 the auction becomes more competitive and the chance of winning drops. When

383 periodicity is higher, there are more auctions at each round. Therefore, the bidders have 
384 more auctions to choose from at each round. Consequently, bidders tend to bid only on

385 the amount they need as defined by Equation (2) to (5). Hence, they may lose

386 opportunities by not participating in other auctions. Therefore, bidders tend to win lower

387 volumes when there are more auctions in one round. Again, these results are intuitive and

388 tend to validate the model. The next sections delve further into the comparison of

389 combinatorial and single-unit timber auctions.

\section{$390 \quad 4.4 \quad$ Analysis 3 - Average unit price comparison}

391 In this section, we use the results of the simulation carried out with the combinatorial

392 model, and compare them with the results of the single-unit auction from Farnia et al.

393 (2013) with respect to the average unit price by calculating the relative gain of using

394 combinatorial auctions expressed as a percentage of the average unit price of the single-

395 unit auction (Equation 8):

396

$$
\text { Relative gain } P=100 \times\left(\frac{\text { Average unit price }(\text { combinatorial auction })}{\text { Average unit price }(\text { single-unit auction })}-1\right)
$$

397 In order to perform this analysis, we again consider the number of auctions, periodicity,

398 lot size, and the number of bidders. Figure 3 displays the impact of these parameters.

399 First, the combinatorial auction is preferable to the single-unit auction when the number

400 of auctions increases. Although the number of auctions has a negative impact on the

401 average unit price in the combinatorial auction, the combinatorial auction tends to

402 dampen this effect compared to the single-unit auction. In other words, the ability of the

403 combinatorial auction to obtain the maximum value from the products present on a stand

404 allows the seller to minimize this negative impact. Similarly, the combinatorial auction is 405 preferable to the single-unit auction when there are fewer bidders. Again, fewer bidders 
406 leads to decreased competition and, therefore, smaller revenue (i.e., average unit price).

407 For the same reason, the combinatorial auction is able to obtain higher revenue than the

408 single-unit auction. This impact is again similar to large lot sizes, which increase the offer.

409 Together, these results tend to show that the relative gain of combinatorial auction

410 increases when market conditions are not favourable for the seller (i.e., low competition).

411 Furthermore, this phenomenon is exacerbated when the difference between potential

412 supply and demand is larger. For example, when there are 250 auctions and 150 bidders

413 in the market, the difference between the outcomes of both types of auctions is not

414 significant.

415 Concerning the impact of periodicity of the auction (i.e., number of days between two

416 rounds of auction), the higher the delay between two rounds, the more favourable the

417 combinatorial auction. This can be explained using the same logic. When the delay is

418 large (30 days), there are more items for sale at each round (the total number of auctions

419 and bidders remaining the same). This creates a situation of low competition that tends to

420 favour combinatorial auction. However, for a periodicity of 7 or 15 days, there are fewer

421 items for sale leading to a higher competition, which favour the single-unit auction.

\section{$422 \quad 4.5$ Analysis 4-Procurement target achievement comparison}

423 In this section, we compare combinatorial and single-unit auctions with respect to target

424 achievement. To do so, we similarly calculate the relative gain from using the

425 combinatorial auction expressed as a percentage of the target achievement of the single-

426 unit auction (Equation 9).

427 Relative gain $T A=100 \times\left(\frac{\text { Target achievement }(\text { combinatorial auction })}{\text { Target achievement }(\text { single-unit auction })}-1\right)$ 
428 Figure 4 presents the impact of each parameter on the procurement target achievement.

430 Here, contrary to the previous section, the gain concerns the bidders. However, the 431 combinatorial auction is preferable in similar market conditions (i.e., low competition); in

432 other words, when the number of auctions is high and the number of bidders is low. For 433 the same reason, the combinatorial auction is also favourable when the lot size is larger, 434 and when there are more items in the market. However, concerning the impact of 435 periodicity (delay between two rounds of auction), the effect is different. In other words, 436 although the combinatorial auction remains favourable over the single-unit auction, a 437 long delay (30 days) between two rounds of auctions tends to diminish the benefit of the 438 combinatorial auction with respect to target achievement. This can be explained 439 differently. Bidder agents are programmed in order to find a compromise between 440 learning market value, and adapting to achieve their procurement target. To adapt, 441 bidders adjust the value of their bid at each round of auction (first two elements of

442 Equation (6)). If there are fewer rounds because periodicity is high, then bidders have 443 fewer opportunities to adapt their bids and win. This phenomenon seems to be slightly 444 exacerbated with the combinatorial auction compared to the single-unit auction.

\section{$445 \quad 4.6$ Discussion}

446 Our results show that the design auction parameters that affect the average unit price of 447 combinatorial auction are the number of auctions, the number of bidders and lot size. 448 These parameters qualitatively affect the single-unit in a similar manner. However, the 449 combinatorial auction average unit price is higher in low-competitive market conditions. 
450 The number of auctions, the number of bidders, periodicity, and lot size also affects the

451 bidders' procurement target achievement. Similar to the average unit price, the target

452 achievement with the combinatorial auction is higher in low-competitive market

453 conditions. This can be explained by the fact that when there are more auctions or fewer

454 bidders, bidders can bid on a variety of bundles directly related to their needs, without

455 impeding the other bidders to do the same. In other words, in combinatorial auctions,

456 bidders can fulfill their needs with a combination of auctions, while in single-unit

457 auctions they bid on fewer auctions and may win species they do not necessarily need. In

458 single-unit auctions, the resale of these species is managed privately and not controlled

459 by the auction itself. This process was not simulated in this platform.

460 However, when analyzed in greater detail, these results show that the combinatorial and

461 single-unit auctions have their different domains of predilection. For example, the 462 combinatorial auction seems to be better suited for market conditions with low 463 competition (e.g., fewer bidders, more auctions), which is generally the case in the 464 Québec timber auction due to the geographical distance of the lots. Because the 465 combinatorial auction allows more companies to simultaneously access timber by bidding 466 on just the products they need, while allowing the seller to get the maximum value from a 467 forest stand, it seems better suited for the Québec timber procurement context than the 468 single-unit auction. Of course, more work is required to validate this finding. For instance, 469 the scale economies associated with large lot sizes was not modelled in this study. It is 470 not clear whether this could affect the result. Along this line, the coordination of harvest 471 operations when there are several winners for one forest stand may also affect the overall 472 results by increasing total cost of ownership, which is not taken into account here. 
473 Similarly, the complexity of the implementation of combinatorial auction may lead to

474 unknown outcomes worth investigating. For example, in some provinces of Canada, there

475 are overlapping tenures (where different species are allocated to different companies),

476 and this system has many problems related to enforcement of harvesting and management

477 regulations.

\section{Conclusion and Future Studies}

479 This paper presents a study of a multiple-round timber combinatorial auction using a 480 multi-agent simulation platform. The performance of the auction was tested in various 481 setup configurations to analyze the impacts of different configurations. Two main 482 indicators were used to measure the performance of the model. The average unit price $483\left(\$ / \mathrm{m}^{3}\right)$ evaluates the seller's ability to generate revenue. Next, procurement target 484 achievement evaluates the bidder's capability to fulfill their needs from auctions. We also 485 analyzed these indicators in order to compare the combinatorial and single-unit auctions.

486 The results shown in the previous sections present several interesting features. First, the 487 auction design parameters affects the impacts of both the combinatorial and single-unit 488 auctions for the seller and the bidders in a similar manner. Second, when the number of 489 bidders increases, so does competition, which in turn increases the average unit price and 490 decreases the bidder's ability to achieve their procurement target.

491 There are some limitations of the study that should be considered. Although the 492 combinatorial auction seems interesting, the Québec ministry of natural resources must 493 assess the current competitive state of the timber market in order to know whether the 494 combinatorial auction approach is a relevant solution. Furthermore, one of the downsides 
495 of combinatorial auctions concerns the possibility of leftover products in a lot, which will

496 be addressed in future work. For instance, leftover products could be considered in the

497 winner determination problem. In other words, the winner determination problem could

498 consider the highest combination of bids that includes a minimum percentage of the total

499 volume of the lot. Similarly, future work must take various lot sizes into account and

500 include all associated costs, such as harvest and coordination costs. Furthermore, one of

501 the limitations of the study is that the timber lots consist of four species. The study can be

502 investigated to see what are the consequences of auctioning the lots with more than four

503 different species in timber combinatorial auctions. The other limitation of our work is that

504 the advantages of our approach in terms of increased revenues and accomplished targets

505 to either party of an auction is not weighed against the costs of logging equipment

506 deployment and damage to any remaining trees. This issue can be addressed in future 507 studies.

508

509 Acknowledgements:

510 The FOR@C Research Consortium, and the NSERC funded this work. The contribution

511 of the experts at the Bureau de mise en marché des bois, of the Québec government is

512 also acknowledged for their advices, explanations, and validation of the models.

\section{References:}

514 Athey, S., Levin, J., 2001. Competition and information in us forest service timber 515 auctions. Journal of Political Economy, 109(2), 375-417. 
516 Athey, S., Levin, J., Seira, E., 2011. Comparing open and sealed bid auctions: evidence

517 from timber auctions. The Quarterly Journal of Economics, 126(1), 207-257.

518 Baldwin, L. H., Marshall, R. C., Richard, J. F., 1997. Bidder collusion at forest service

519 timber sales. Journal of Political Economy, 105(4), 657-699.

520 Brewer, P. J. (1999). Decentralized computation procurement and computational 521 robustness in a smart market. Economic Theory, 13(1), 41-92.

522 Cramton, P., Shoham, Y., and Steinberg, R., editors, 2006. Combinatorial Auctions. MIT 523 Press.

524 De Vries, S., \& Vohra, R. V. (2003). Combinatorial auctions: A survey. INFORMS 525 Journal on computing, 15(3), 284-309.

526 Elyakime, B., Laffont, J. J., Loisel, P., Vuong, Q., 1997. Auctioning and bargaining: an 527 econometric study of timber auctions with secret reservation prices. Journal of Business 528 \& Economic Statistics, 15(2), 209-220.

529 Farnia. F., J.M. Frayret, L. LeBel, C. Beaudry, 2013 "Multiple-Round Timber Auction 530 Design and Simulation," International Journal of production economics, 146(1), 129-141.

531 Farnia. F., J.M. Frayret, C. Beaudry, L. LeBel, 2015 "Time-Based Combinatorial Auction 532 for Sustainable Timber Allocation and Delivery Coordination," Forest Policy and 533 Economics, 50(1), 143-152.

534 Ghassemi Tari, F., Alaei, R., 2013. "Scheduling TV commercials using genetic 535 algorithms,” International Journal of Production Research, 51(16), 4921-4929.

536 Grossklags, J., Schmidt, C., Siegel, J., 2000. Dumb software agents on experimental 537 electronic markets. In: Informatiktage 2000, G. fur Informatik e.V.,Ed. Leinfelden538 Echterdinge, Germany: Konradin Verlag.

539 Haile, P., 2001. Auctions with resale markets: an application to us forest service timber 540 sales. American Economic Review, 91, 399-427. 
541 Hansen, R., 1985. Empirical testing of auction theory. American Economic Review, 75, $542 \quad 156-159$.

543 Jung, S. H., \& Kim, K. H., 2006. Load scheduling for multiple quay cranes in port 544 container terminals. Journal of Intelligent manufacturing, 17(4), 479-492.

545 Kutanoglu, E., \& Wu, S. D. (1999). On combinatorial auction and Lagrangean relaxation 546 for distributed resource scheduling. IIE transactions, 31(9), 813-826.

547 Kwon, R. H., Lee, C. G., \& Ma, Z. (2005). An integrated combinatorial auction 548 mechanism for truckload transportation procurement. University of Toronto, http://www. 549 mie. utoronto. ca/labs/ilr/MultiRound. pdf, Working Paper.

550 Lau, H. C., Cheng, S. F., Leong, T. Y., Park, J. H., \& Zhao, Z., 2007. Multi-period 551 combinatorial auction mechanism for distributed resource allocation and scheduling. In 552 Proceedings of the 2007 IEEE/WIC/ACM International Conference on Intelligent Agent 553 Technology (407-411). IEEE Computer Society.

554 Mead, W. J., 1967. Natural resource disposition policy: oral auctions vs. sealed bids. 555 Natural Resource Journal, 7, 194-224.

556 Munn, I. A., \& Rucker, R. R. (1995). An economic analysis of the differences between 557 bid prices on Forest Service and private timber sales. Forest Science,41(4), 823-840.

558 Paarsch, H.J., 1997. Deriving an estimate of the optimal reserve price: an application to 559 British Columbian timber sales. Journal of Econometrics, 78(2), pp.333-357

560 Parkes, D. (2006). Iterative combinatorial auctions. Combinatorial auctions, 41-77.

561 Rassenti, S.J., Smith, V.L., Bulfin, R.L., 1982. A Combinatorial Auction Mechanism for 562 Airport Time Slot Allocation. The Bell Journal of Economics, 13(2), 402-417.

563 Shoham, Y., Leyton-Brown, K., 2009. Multiagent systems: algorithmic, game-theoretic, 564 and logical foundations. Cambridge University Press.

565 Vidal, J. M., 2007. Fundamentals of multiagent systems with NetLogo examples. 
566 Wang, C., Dargahi, F., 2013. Service customization under capacity constraints: An 567 auction-based model, Journal of Intelligent Manufacturing, 24(5), 1033-1045.

568 Wooldridge, M., \& Jennings, N. R. (1995). Intelligent agents: Theory and practice. The 569 knowledge engineering review, 10(02), 115-152. 
Table 1: Sets and indexes of the model

\begin{tabular}{|l|l|}
\hline$j$ & bidders \\
\hline$i \in G$ & set of lots \\
\hline$S \subseteq G$ & bundles of lots \\
\hline$M P_{j, S}$ & maximum price of bidder $\mathrm{j}$ for bundle $\mathrm{S}$ \\
\hline$N P_{j, S}$ & minimum price of bidder $\mathrm{j}$ for bundle $\mathrm{S}$ \\
\hline$R P_{S}$ & reserve price of bundle $\mathrm{S}$ \\
\hline$V_{S}$ & volume of bundle $\mathrm{S}$ \\
\hline$M R P_{S}$ & average revenue from the final products of all species of bundle $\mathrm{S}$ \\
\hline$H C_{S}$ & harvest cost of bundle $\mathrm{S}$ \\
\hline$D_{j, S}$ & distance of the bundle $S$ to bidder $j$ \\
\hline$T C_{S}$ & transportation cost of bundle $\mathrm{S}$ \\
\hline$P C_{j, S}$ & average cost of processing bundle $S$ into the final product of bidder $j$ \\
\hline$P R_{j, S}$ & minimum profit that bidder $\mathrm{j}$ is willing to gain from bundle $\mathrm{S}$ \\
\hline$N D_{j, S}$ & need of bidder $j$ at time $t$ for bundle $S$ \\
\hline
\end{tabular}

570 

Table 2: Analysis of variance for price from the combinatorial auctions

\begin{tabular}{|c|c|c|c|c|}
\hline \multirow{3}{*}{$\begin{array}{r}\text { Number of observations }= \\
\text { Root MSE }=\end{array}$} & \multicolumn{4}{|c|}{$R^{2}=0.8$} \\
\hline & 0.10 & Adjusted $R^{2}$ & .80 & \\
\hline & Partial SS & $M S$ & $\boldsymbol{F}$ & Prob $>F$ \\
\hline Model & 86.59 & 2.7 & 249.0 & $<0001$ \\
\hline Number of Auctions & 0.33 & 0.16 & 15.09 & $<0001$ \\
\hline Periodicity & 0.02 & 0.01 & 0.74 & 0.48 \\
\hline Lot Size & 0.17 & 0.08 & 7.76 & 0.00 \\
\hline Number of Bidders & 10.99 & 5.50 & 505.80 & $<0001$ \\
\hline Number of Auctions \# Periodicity & 0.02 & 0.01 & 0.50 & 0.74 \\
\hline Number of Auctions \# Lot Size & 0.11 & 0.03 & 2.63 & 0.03 \\
\hline $\begin{array}{l}\text { Number of Auctions \# Number of } \\
\text { Bidders }\end{array}$ & 0.01 & 0.00 & 0.34 & 0.85 \\
\hline Periodicity \# Lot Size & 0.01 & 0.00 & 0.26 & 0.90 \\
\hline Periodicity \# Number of Bidders & 0.05 & 0.01 & 1.08 & 0.37 \\
\hline Lot Size \# Number of Bidders & 0.04 & 0.01 & 1.03 & 0.39 \\
\hline Residual & 21.64 & 0.01 & & \\
\hline
\end{tabular}


574 Table 3: Analysis of variance for the procurement target achievement of bidders with 575 combinatorial auctions

\begin{tabular}{|c|c|c|c|c|c|}
\hline \multirow[t]{2}{*}{ Number of observations $=$} & \multirow{2}{*}{$\begin{array}{l}2025 \\
0.02 \\
\text { Partial SS }\end{array}$} & \multicolumn{3}{|c|}{$\begin{array}{l}R^{2}=0.98 \\
\text { Adjusted } R^{2}=0.98\end{array}$} & \multirow[b]{2}{*}{ Prob $>F$} \\
\hline & & $D F$ & $M S$ & $F$ & \\
\hline Model & 65.35 & 32.0 & 2.04 & 3922.83 & $<<0001$ \\
\hline Number of Auctions & 6.89 & 2.00 & 3.44 & 6614.35 & $<.0001$ \\
\hline Periodicity & 0.03 & 2.00 & 0.01 & 26.89 & $<.0001$ \\
\hline Lot Size & 1.02 & 2.00 & 0.51 & 977.92 & $<.0001$ \\
\hline Number of Bidders & 0.05 & 2.00 & 0.03 & 51.57 & $<0001$ \\
\hline Number of Auctions \# Periodicity & 0.23 & 4.00 & 0.06 & 112.55 & $<.0001$ \\
\hline Number of Auctions \# Lot Size & 2.21 & 4.00 & 0.55 & 1061.44 & $<.0001$ \\
\hline $\begin{array}{l}\text { Number of Auctions \# Number of } \\
\text { Bidders }\end{array}$ & 2.91 & 4.00 & 0.73 & 1399.39 & $<.0001$ \\
\hline Periodicity \# Lot Size & 0.04 & 4.00 & 0.01 & 17.59 & $<.0001$ \\
\hline Periodicity \# Number of Bidders & 0.05 & 4.00 & 0.01 & 25.13 & $<.0001$ \\
\hline Lot Size \# Number of Bidders & 0.82 & 4.00 & 0.21 & 395.66 & $<0001$ \\
\hline Residual & 1.04 & 1992 & 0.00 & & \\
\hline Total & 66.38 & 2024 & & & \\
\hline
\end{tabular}


578 LIST OF FIGURES:

579 FigURE 1: AVERAGE UNIT PRICE FROM THE COMBINATORIAL AUCTIONS; (A) IMPACT OF THE 580 NUMBER OF AUCTIONS; (B) IMPACT OF THE LOT SIZE; (C) IMPACT OF THE NUMBER OF 581 BIDDERS.

582 FIGURE 2: ANALYSIS OF THE PROCUREMENT TARGET ACHIEVEMENT OF BIDDERS FROM 583 COMBINATORIAL AUCTIONS: (A) EFFECT OF THE NUMBER OF AUCTIONS, (B) EFFECT OF 584 LOT SIZE, AND (C) EFFECT OF THE NUMBER OF BIDDERS

585 FIgURE 3: COMPARATIVE ANALYSIS OF AVERAGE UNIT PRICE AS A FUNCTION OF (A) THE 586 NUMBER OF AUCTIONS, (B) LOT SIZE, (C) THE NUMBER OF BIDDERS, AND (D) 587 PERIODICITY (DELAY BETWEEN TWO ROUNDS)

588 FIGURE 4: COMPARATIVE ANALYSIS OF PROCUREMENT TARGET ACHIEVEMENT AS A 589 FUNCTION OF (A) THE NUMBER OF AUCTIONS, (B) LOT SIZE, (C) THE NUMBER OF 590 BIDDERS, AND (D) PERIODICITY (DELAY BETWEEN TWO ROUNDS) 
592 Figure 1: Average unit price from the combinatorial auctions; (a) impact of the number of 593 auctions; (b) impact of the lot size; (c) impact of the number of bidders.

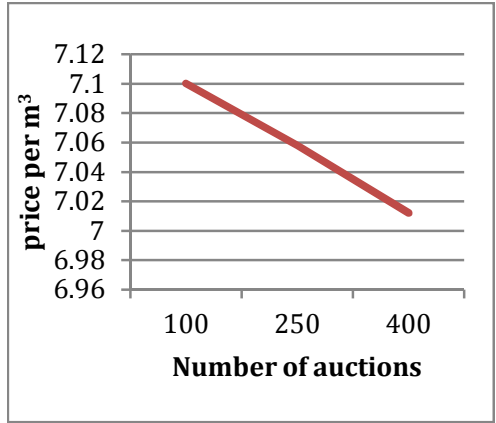

a)

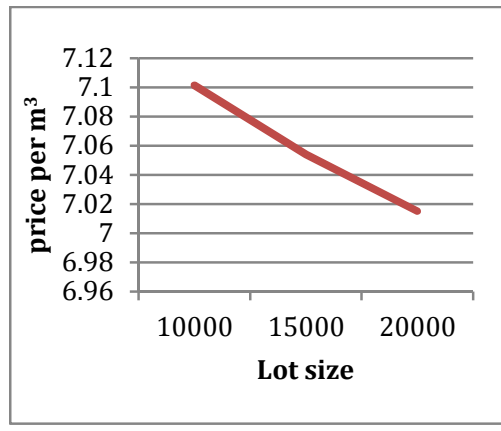

b)

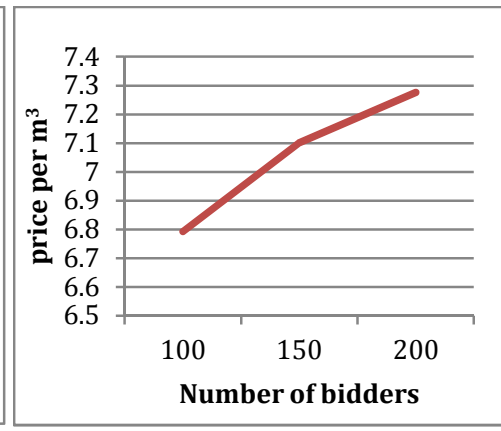

c) 
595 Figure 2: Analysis of the procurement target achievement of bidders from combinatorial 596 auctions: (a) effect of the number of auctions, (b) effect of lot size, and (c) effect of the 597 number of bidders

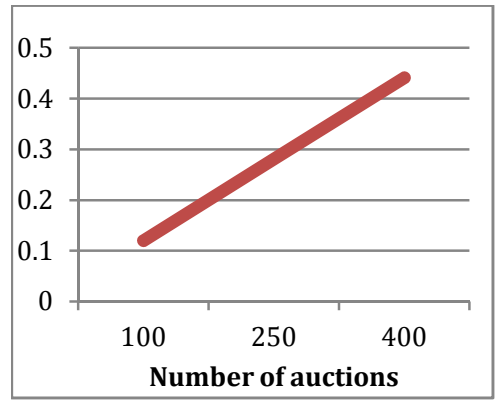

a)

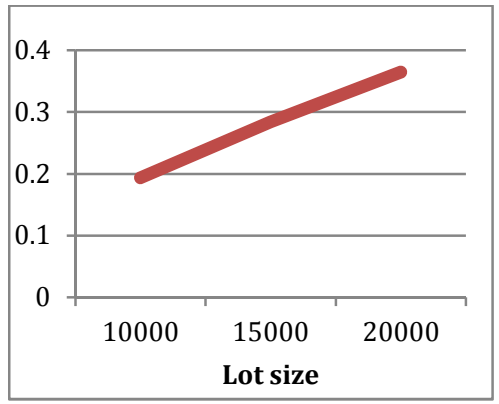

b)

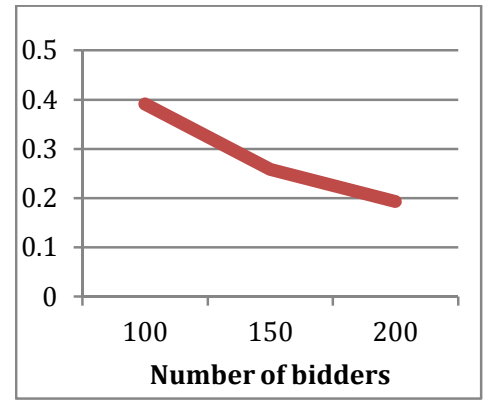

c) 
599 Figure 3: Comparative analysis of average unit price as a function of (a) the number of 600 auctions, (b) lot size, (c) the number of bidders, and (d) periodicity (delay between two 601 rounds)

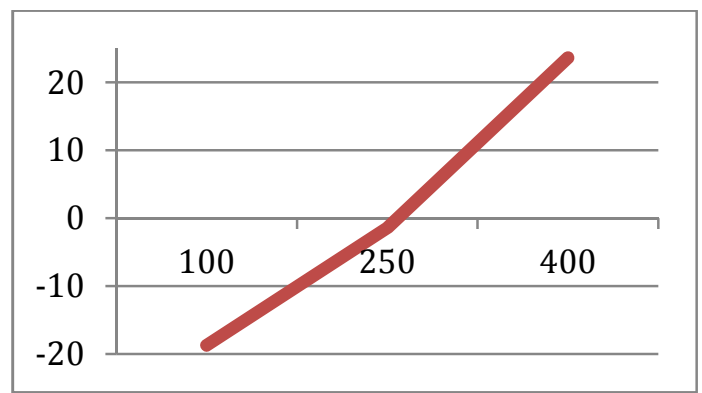

a)

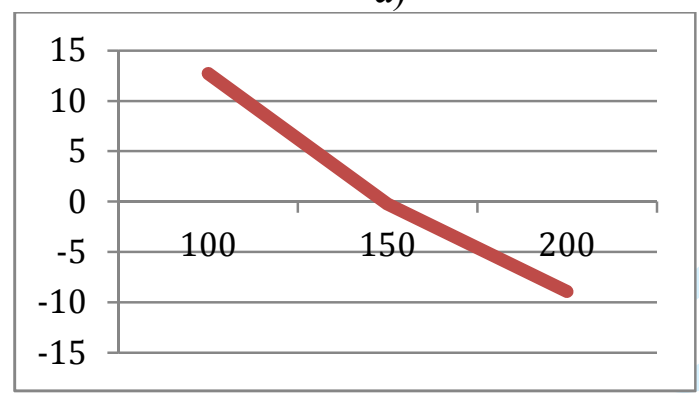

c)

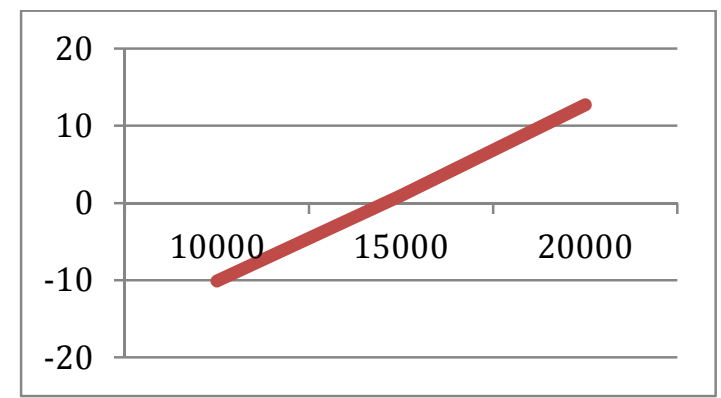

b)

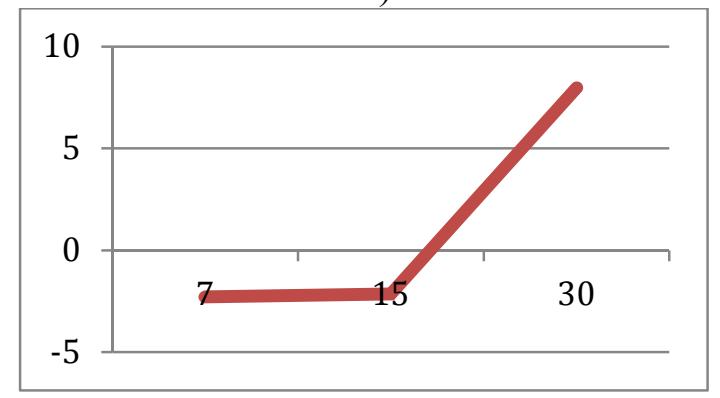

d) 
603 Figure 4: Comparative analysis of procurement target achievement as a function of (a) 604 the number of auctions, (b) lot size, (c) the number of bidders, and (d) periodicity (delay 605 between two rounds)

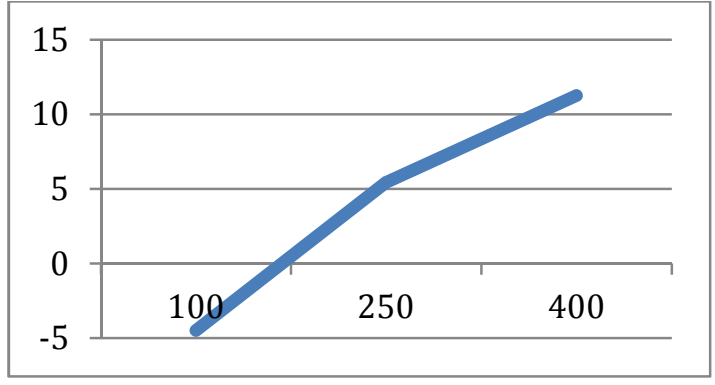

a)

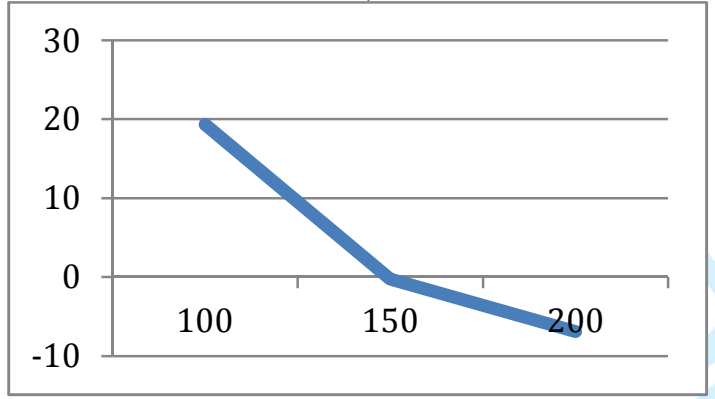

c)

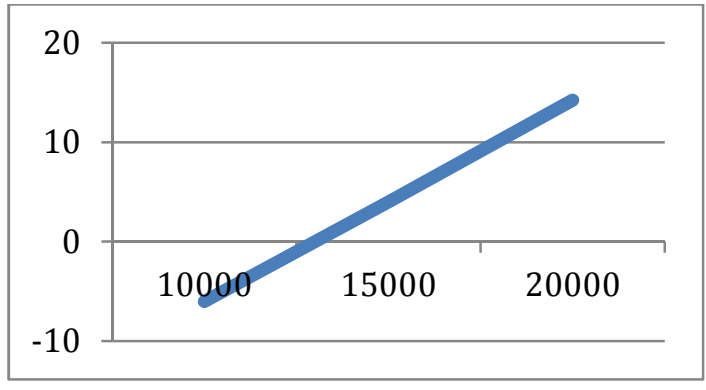

b)

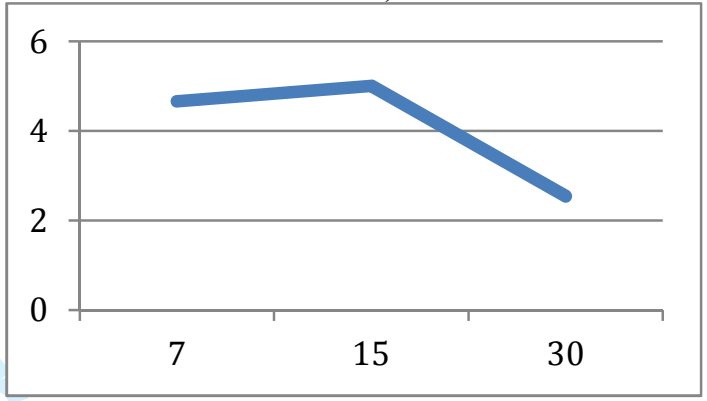

d)

606 
608 This appendix presents the winner determination procedure.

609

610 Let

611

$612 \mathrm{~J}$ be number of bidders;

$613 v_{j, s 1}$ be bidder j's value of $\mathrm{s} 1$;

$614 v_{j, s 2}$ be bidderj's value of $\mathrm{s} 2$;

$615 v_{j, h 1}$ be bidder j's value of $\mathrm{h} 1$;

$616 v_{j, h 2}$ be bidder j's value of h2;

$617 v_{j, s 1 s 2}$ be bidder j's value of s1s2;

$618 v_{j, h 1 h 2}$ be bidder j's value of h1h2;

$619 v_{j, s 1 s 2 h 1 h 2}$ be bidder j's value of s1s2h1h2;

$620 \quad w_{s 1}$ be the winner of 1 ;

$621 w_{s 2}$ be the winner of 2 ;

$622 w_{h 1}$ be the winner of $h 1$;

$623 w_{h 2}$ be the winner of $h 2$;

$$
v_{s 1}=v_{s 2}=v_{h 1}=v_{h 2}=v_{s 1 s 2}=v_{h 1 h 2}=0
$$

$$
\text { for } j=1 \text { to } J \text { do }
$$

630

$$
\begin{aligned}
& v_{s 1}=\max \left(v_{s 1}, v_{j, s 1}\right) \\
& v_{s 2}=\max \left(v_{s 2}, v_{j, s 2}\right)
\end{aligned}
$$




$$
v_{h 1}=\max \left(v_{h 1}, v_{j, h 1}\right)
$$

$$
v_{h 2}=\max \left(v_{h 2}, v_{j, h 2}\right)
$$

$$
v_{s 1, s 2}=\max \left(v_{s 1, s 2}, v_{j, s 1, s 2}\right)
$$

$$
v_{h 1, h 2}=\max \left(v_{h 1, h 2}, v_{j, h 1, h 2}\right)
$$

$$
w_{s l}=\mathrm{j} \mid v_{s l}=v_{j, s l} \text { and } j \in[1, \mathrm{~J}]
$$

$$
w_{s 2}=\mathrm{j} \mid v_{s 2}=v_{j, s 2} \text { and } j \in[1, \mathrm{~J}]
$$

$$
v_{s 1 s 2}=v_{s 1}+v_{s 2}
$$

else

$$
w_{s 1}=w_{s 2}=\mathrm{j} \mid v_{s 1 s 2}=v_{j, s 1 s 2} \text { and } j \in[1, \mathrm{~J}]
$$

$$
\text { If } v_{h 1}+v_{h 2}>v_{h 1 h 2} \text { then }
$$

$$
w_{h 1}=\mathrm{j} \mid v_{h 1}=v_{j, h 1} \text { and } j \in[1, \mathrm{~J}]
$$

$$
w_{h 2}=\mathrm{j} \mid v_{h 2}=v_{j, h 2} \text { and } j \in[1, \mathrm{~J}]
$$

$$
v_{h 1 h 2}=v_{h 1}+v_{h 2}
$$

else 
654 If $v_{s 1 s 2}+v_{h 1 h 2}<v_{s 1 s 2 h 1 h 2}$ then

655

$$
w_{s 1}=w_{s 2}=w_{h 1}=w_{h 2}=\mathrm{j} \mid v_{s 1 s 2 h 1 h 2}=v_{j, s 1 s 2 h 1 h 2} \text { and } j \in[1, \mathrm{~J}]
$$

656

end if

657

]

658 